\title{
Nutrition status and functional prognosis among elderly patients with distal radius fracture: a retrospective cohort study
}

Takako Nagai ( $\nabla$ ntnyf092@yahoo.co.jp )

Nihon Daigaku Byoin

Koji Tanimoto

Nihon Daigaku Byoin

Yoshiaki Tomizuka

Nihon Daigaku Byoin

Hiroshi Uei

Nihon Daigaku Byoin

Masahiro Nagaoka

Nihon Daigaku Byoin

\section{Research article}

Keywords: Distal radius fracture, falls, nutritional status, activity of daily living, geriatric

Posted Date: February 20th, 2020

DOl: https://doi.org/10.21203/rs.2.24097/v1

License: @ (1) This work is licensed under a Creative Commons Attribution 4.0 International License. Read Full License

Version of Record: A version of this preprint was published at Journal of Orthopaedic Surgery and Research on April 7th, 2020. See the published version at https://doi.org/10.1186/s13018-020-01657-y. 


\section{Abstract}

Background : Distal radius fractures (DRF) are common in the elderly and are typical of hand fractures during falls. Malnutrition has also been identified as a poor prognostic factor in elderly patients with fractures. However, the relationship between nutritional status and subsequent falls and functional prognosis for DRF in the elderly is not clear. The aim of the present study was to investigate the association between nutritional status and functional prognosis in elderly patients with DRF.

Methods : Study participants included 229 outpatients who required surgical treatment for DRF. The patients' clinical information, including age, sex, body mass index, bone mineral density, Geriatric Nutritional Risk Index (GNRI), total number of drugs being treated with on admission, use of drugs for osteoporosis, comorbidity severity, the Barthel Index (BI), presence of subsequent falls, fracture type, postoperative follow-up period, and Mayo wrist score was reviewed. Subjects were further divided into two groups according to their GNRI: the malnutrition group and the normal group. Propensity score matching was used to confirm factors affecting the BI and subsequent falls.

Results: Thirty-one patients (13.5\%) presented with malnutrition before surgery for DRF. According to multiple liner regression analysis, the GNRI positively affected the efficiency of the $\mathrm{BI}(\beta=0.392,95 \%$ confidence interval [Cl], 0.001 to $0.351, p=0.039)$. Furthermore, on logistic regression analysis, subsequent falls were associated with serum albumin levels (odds ratio $=0.033,95 \% \mathrm{Cl}, 0.002$ to $0.477, p=0.012$ ).

Conclusion : Malnutrition impaired improvement of activities of daily living (ADL) and increased the incidence of subsequent falls. Improvement of nutritional status before DRF surgery may further improve ADL and prevent falls.

\section{Background}

Distal radius fracture (DRF) is the most common fragility fracture and is typically caused by a fall on an outstretched hand $[1,2]$. There are two major age peaks for DRF: high-energy injuries deriving from sports injuries in young people and falls in older individuals [3]. As the life span of the general population increases, the incidence of DRF in the elderly is increasing [4]. In addition, elderly DRF patients are at highrisk of subsequent falls $[5,6]$. It has been reported that decreased activity due to pain after DRF and fear of falling may cause a decline in muscle strength and balance, which may be a risk factor for future falls [7, 8]. A large clinical cohort of individuals followed for 10 years showed that those with a DRF had $11 \%$ more fractures than those without a prior fracture [9]. The association between DRF and subsequent fractures is independent of other osteoporosis risk factors. Non-modifiable factors such as age, sex, and prior fall history are wellestablished predictors of subsequent falls $[10,11]$.

More recently, bone density has been reported to be associated with risk factors for DRF and factors associated with falls after DRF [12, 13]. Low bone mineral density has also been reported in malnutrition $[14,15]$, while Adly et al. have reported that malnutrition increased the risk of falls [16]. However, there have been no reports describing the relationship between nutritional status and DRF or factors associated with falls after DRF.

This study hypothesized that there is an association between nutritional status and fall risk and impact on activities of daily living (ADL) after DRF. Further, the study examined the relationship between nutritional status after DRF and functional prognosis.

\section{Materials And Methods}

\section{Study design and participants}

Th retrospective study enrolled 229 patients aged 65 years or older presenting DRF admitted to an acute care hospital between October 2014 and December 2018 who underwent surgery and follow-up for at least 1 year after surgery. Patients were retrospectively identified via a search of the surgical database at our two affiliated hospitals. Demographic and postoperative clinical course information was extracted from each patient's electronic medical record. Patients with neurological/cognitive impairment, multiple fractures, death, and missing data including bone density that could not be accurately measured after spine surgery were excluded. Ethical approval was obtained from each hospital's ethics board. Patient informed consent was not required due to the retrospective design of the study.

\section{Surgical treatment and rehabilitation}

All patients were treated with internal fixation using a volar locking plate (ACU-LOC plate, ACUMED, LLC., USA, $n=88$ cases; Anatomic Volar Plate System. Depuy Synthes, Johnson- Johnson. Co., USA, $n=75$ cases; Stellar2, HOYA Technosurgical Co., Japan, $n=42$ cases, and APUTUS 2.5, Medical engineering system Co., Japan, $n=24$ cases). A standard volar approach was used to expose the fracture side. The fracture was approached from the radial side of the flexor carpi radialis, and the quadrate pronator muscle was incised to reduce the fracture. If the fracture was unstable, it was reduced with Kirschner wire. Following the surgery, all patients were casted for 3-7 days 
depending on the stability of the fracture site. In postoperative rehabilitation, finger excursion training was started from the day after the operation. Active and passive training of the wrist joint with one-to-one guidance were started after cast removal.

\section{Measurements}

Information collected for all patients included age, sex, body mass index (BMI), total number of drugs administered on admission, number and type of potentially inappropriate medications (PIMs) on admission, bone mineral density (as a percentage of the mean values for young adults), fracture type, comorbidity severity (Charlson Comorbidity Index, CCI), nutritional status (Geriatric Nutritional Risk Index, GNRI), wrist function criteria (Mayo Wrist Score), Barthel Index (BI), presence of subsequent falls, and follow-up periods after surgery.

Osteoporosis was defined as a T-score less than and equal to - 2.5 SD in the lumber vertebrae (L2-4). The AO classification was used to describe the DRF type. This classification system is commonly used for the radiographic classification of DRF and includes three types: A, B, and C. A is an extra-articular fracture, B is an intra-articular fracture, and C is an intra-articular complete fracture.

Comorbidity was assessed using the $\mathrm{CCI}$ [17]. The $\mathrm{CCl}$ is an indicator of multi-disease comorbidities and includes diabetes with chronic complications, heart failure, kidney disease, liver disease, chronic lung disease, dementia, hemiplegia or paraplegia, malignancy, and AIDS/HIV. The CCl uses a weighted score for each comorbidity, with higher numbers indicating a greater number of comorbidities and greater risk of mortality.

GNRI was calculated using the formula proposed by Bouillanne et al [18]:

$14.89 \times$ serum albumin $(\mathrm{g} / \mathrm{dL})+\{41.7 \times$ (current/ideal body weight) $\}$.

Individuals with GNRI less than 92 were assigned to the malnutrition group, and those with GNRI more than 92 were assigned to the normal group with mild or no risk of malnutrition.

$\mathrm{ADL}$ were evaluated by the $\mathrm{BI}$. The $\mathrm{BI}$ is an assessment of 10 items: eating, moving, dressing, toilet movement, bathing, walking, going up and down stairs, changing clothes, defecation, and urination. Each item is scored as 0: unable to complete; 1: needs help; or 2: independent, and the total score is multiplied by 20 , for a maximum score of 100 . ADL was assessed before surgery and at the final follow-up. BI efficacy was defined by the $\mathrm{BI}$ at the end of follow-up minus the preoperative BI. The Mayo wrist score was used for wrist function evaluation. The scale includes scores for pain, functional status, range of motion, and grip strength, with a total score of 0 to 100 . The higher the score, the better the function.

Subsequent falls were defined as falls caused by carelessness and did not include falls caused by traffic accidents, brain injuries, or diseases such as epilepsy.

\section{Outcomes}

The primary outcome was BI gain, which was defined as the difference in the total $\mathrm{BI}$ at one year after surgery from that on admission. The secondary outcome was subsequent falls during follow up periods.

\section{Statistical analysis}

The subjects were divided into two groups: the malnutrition group and the normal group. The unpaired t-test, Mann-Whitney's U-test, and $\chi 2$ test were used for comparison between the two groups, depending on variables and normality. Spearman's rank correlation was used for univariate analysis of $\mathrm{BI}$ at final evaluation. Logistic regression analysis was also performed to determine whether the dependent variable was the presence or absence of a subsequent fall. As the number in the malnutrition group was small, the number of variables included in the logistic model had to be reduced. Propensity scores were calculated by logistic regression analysis including age, sex, comorbidity index, number of drugs, and fracture type as explanatory variables. All analyses were performed using IBM SPSS Statics version 25 (IBM Corporation; Armonk, NY, USA). A P-value less than 0.05 was considered statistically significant.

\section{Results}

During the study period, a total of 229 patients were eligible for participation. Patient characteristics are shown in Table 1. Thirty-one patients (37.2\%) were in the malnutrition group. The malnutrition group had a lower $\mathrm{BMI}$, serum albumin, and $\mathrm{BI}$ score $(\mathrm{p}<0.001)$, and a higher number of subsequent falls and a $\mathrm{CCl}(p<0.001, p=0.006$, respectively) than the normal group. Postoperative complications of $\mathrm{DRF}$

Page $3 / 9$ 
are shown in Table 2. In the malnutrition group, the rates of extensor pollicis longus (EPL) rupture, screw loosening, compression, and neuropathy were significantly higher than in the normal group. The cause of EPL rupture did not include, for the majority, screw dorsal cortex penetration or dorsal cortex comminution. The Spearman's rank correlation results are shown in Table 3. GNRI was correlated with BMI, serum albumin, subsequent fall, BI at admission, and BI efficacy. BI efficacy was correlated with GNRI, serum albumin, and CCI, but not age, BMD and Mayo wrist score. There was no significant correlation between BMD and each factor, but the correlation coefficient was negative for $\mathrm{CCl}$ and fall during the follow-up period. Patients with complications and falls during the follow-up periods were considered to have lower BMD.

Table 1

Patients characteristics

\begin{tabular}{|c|c|c|c|c|}
\hline & All $(n=229)$ & $\begin{array}{l}\text { GNRI } \geq 92 \\
(n=198)\end{array}$ & $\begin{array}{l}\text { GNRI }<92 \\
(n=31)\end{array}$ & p-value \\
\hline Age (yr) & $72.0 \pm 8.1$ & $76.1 \pm 8.4$ & $73.5 \pm 8.1$ & $0.770^{1)}$ \\
\hline Sex, female & 198(86.5) & 168(84.8) & $30(96.8)$ & $0.194^{2)}$ \\
\hline Fracture type & & & & $0.903^{2)}$ \\
\hline AO type $A$ & $13(5.6)$ & $11(5.5)$ & $2(6.5)$ & \\
\hline type B & $82(35.8)$ & $70(35.4)$ & $12(38.7)$ & \\
\hline type C & $134(58.5)$ & $117(59.1)$ & $17(54.8)$ & \\
\hline $\mathrm{BMI}(\mathrm{kg} / \mathrm{m} 2)$ & $21.9 \pm 3.9$ & $22.8 \pm 3.7$ & $18.6 \pm 2.6$ & $<0.001^{1)}$ \\
\hline Serum albumin (g/dl) & $4.08 \pm 0.38$ & $4.18 \pm 0.28$ & $3.47 \pm 0.37$ & $<0.001^{1)}$ \\
\hline $\operatorname{BMD}\left(\mathrm{g} / \mathrm{cm}^{2}\right)$ & $0.881 \pm 0.143$ & $0.885 \pm 0.144$ & $0.860 \pm 0.136$ & $0.364^{1)}$ \\
\hline $\mathrm{CCl}$ & $1(0-2)$ & $1(0-2)$ & $1(0-2)$ & $0.006^{2)}$ \\
\hline Total number of drugs administered on admission & $4(0-14)$ & $4(0-8)$ & $5(0-14)$ & $0.274^{1)}$ \\
\hline Use of drugs for osteoporosis, N (\%) & $36(15.7)$ & $32(16.2)$ & $4(12.9)$ & $0.794^{2)}$ \\
\hline Days between onset and operation & $4.81 \pm 1.6$ & $4.42 \pm 2.1$ & $5.18 \pm 2.1$ & $0.655^{1)}$ \\
\hline \multicolumn{5}{|l|}{ BI score } \\
\hline Admission & $77.2 \pm 7.0$ & $78.4 \pm 6.3$ & $69.8 \pm 7.01$ & $<0.001^{1)}$ \\
\hline One year after surgery & $86.4 \pm 8.9$ & $88.2 \pm 7.8$ & $75.2 \pm 7.4$ & $<0.001^{1)}$ \\
\hline Bl efficacy & $9.2 \pm 5.6$ & $9.8 \pm 5.6$ & $5.3 \pm 2.9$ & $<0.001^{1)}$ \\
\hline \multicolumn{5}{|l|}{ Mayo wrist score } \\
\hline One year after surgery & $84.2 \pm 6.6$ & $84.3 \pm 6.6$ & $83.7 \pm 6.8$ & $0.645^{1)}$ \\
\hline Fall during follow up periods, $\mathrm{N}(\%)$ & $21(9.2)$ & $9(4.5)$ & $12(38.7)$ & $<0.001^{2)}$ \\
\hline \multicolumn{5}{|c|}{ Value are presented as mean \pm standard, deviation or number(\%) or median(interquartile range). } \\
\hline \multicolumn{5}{|c|}{ GNRI: Geriatric Nutritional Risk Indexes, BMI: Body Mass Index, BMD: Bone Mineral Density, } \\
\hline
\end{tabular}


Table 2

Postoperative complications of DRF

\begin{tabular}{|lllll|}
\hline Complications & All(n=229) & $\begin{array}{l}\text { GNRI } \geq 92 \\
(\mathbf{n = 1 9 8 )}\end{array}$ & $\begin{array}{l}\text { GNRI<92 } \\
(\mathbf{n = 3 1 )}\end{array}$ & p-value \\
\hline EPL rupture & $3(1.3)$ & $2(1.0)$ & $1(3.2)$ & $0.024^{1)}$ \\
\hline Screw loosening & $1(0.4)$ & $0(0)$ & $1(3.2)$ \\
\hline Compression & $9(3.9)$ & $6(3.0)$ & $3(9.7)$ \\
\hline Neuropathy & $3(1.3)$ & $3(1.5)$ & $0(0)$ \\
\hline Value are presented as number (\%), GNRI: Geriatric Nutritional Risk Indexes, \\
\hline 1) Chi-squared test.
\end{tabular}

Table 3

Spearman rank correlation coefficients among the factors

\begin{tabular}{|c|c|c|c|c|c|c|c|c|c|c|c|}
\hline & Age & BMI & GNRI & $\begin{array}{l}\text { Serum } \\
\text { albumin }\end{array}$ & $\begin{array}{l}\text { Total } \\
\text { number of } \\
\text { drugs on } \\
\text { admission }\end{array}$ & $\mathrm{CCl}$ & $\begin{array}{l}\text { Bl at } \\
\text { admission }\end{array}$ & $\begin{array}{l}\text { BI } \\
\text { efficacy }\end{array}$ & $\begin{array}{l}\text { Mayo } \\
\text { score }\end{array}$ & $\begin{array}{l}\text { Fall } \\
\text { during } \\
\text { follow } \\
\text { up } \\
\text { periods }\end{array}$ & BMD \\
\hline Age & 1 & 0.000 & -0.107 & $-0.191^{\star *}$ & 0.276 & 0.090 & -0.126 & -0.089 & -0.124 & $0.169^{*}$ & 0.031 \\
\hline BMI & 0.000 & 1 & $0.835^{\star *}$ & $0.193^{\star \star}$ & 0.036 & 0.033 & $0.163^{*}$ & 0.033 & 0.002 & -0.115 & -0.028 \\
\hline GNRI & -0.107 & $0.835^{\star \star}$ & 1 & $0.701^{\star \star}$ & -0.083 & -0.083 & $0.378^{\star \star}$ & $0.206^{\star \star}$ & 0.087 & $-0.353^{\star \star}$ & 0.028 \\
\hline $\begin{array}{l}\text { Serum } \\
\text { albumin }\end{array}$ & $-0.191^{\star *}$ & $0.193^{\star \star}$ & $0.701^{\star \star}$ & 1 & $-0.194^{\star \star}$ & $-0.191^{\star *}$ & $0.462^{\star \star}$ & $0.324^{\star \star}$ & $0.152^{\star \star}$ & $-0.482^{\star \star}$ & 0.032 \\
\hline $\begin{array}{l}\text { Total } \\
\text { number of } \\
\text { drugs on } \\
\text { admission }\end{array}$ & 0.276 & 0.036 & -0.083 & $-0.194^{\star \star}$ & 1 & $0.303^{\star \star}$ & $-0.177^{\star *}$ & -0.053 & $-0.161^{*}$ & 0.058 & -0.067 \\
\hline $\mathrm{CCl}$ & 0.090 & 0.033 & -0.083 & $-0.191^{\star \star}$ & $0.303^{\star \star}$ & 1 & $-0.208^{\star \star}$ & $-0.180^{\star \star}$ & -0.070 & $0.145^{*}$ & -0.058 \\
\hline $\begin{array}{l}\text { Bl at } \\
\text { admission }\end{array}$ & -0.126 & $0.163^{\star}$ & $0.378^{\star \star}$ & $0.462^{\star \star}$ & $-0.177^{\star \star}$ & $-0.208^{\star \star}$ & 1 & -0.006 & 0.039 & $-0.285^{\star \star}$ & -0.044 \\
\hline BI efficacy & -0.089 & 0.033 & $0.206^{* *}$ & $0.324^{\star \star}$ & -0.053 & $-0.180^{\star *}$ & -0.006 & 1 & 0.055 & -0.105 & 0.098 \\
\hline $\begin{array}{l}\text { Mayo } \\
\text { score }\end{array}$ & -0.124 & 0.002 & 0.087 & $0.152^{\star \star}$ & $-0.161^{*}$ & -0.070 & 0.039 & 0.055 & 1 & -0.101 & 0.098 \\
\hline $\begin{array}{l}\text { Fall } \\
\text { during } \\
\text { follow up } \\
\text { periods }\end{array}$ & $0.169^{\star}$ & -0.115 & $-0.353^{\star \star}$ & $-0.482^{\star \star}$ & 0.058 & $0.145^{\star}$ & $-0.285^{\star \star}$ & -0.105 & -0.101 & 1 & -0.046 \\
\hline BMD & 0.031 & -0.028 & 0.028 & 0.032 & -0.067 & -0.058 & -0.044 & 0.098 & 0.098 & -0.046 & 1 \\
\hline \multicolumn{12}{|c|}{$\begin{array}{l}\text { BMI: Body Mass Index, GNRI: Geriatric Nutritional Risk Indexes, CCl: Charlson Comorbidity Index, BI: Barthel index, BMD: Bone Mineral } \\
\text { Density, }\end{array}$} \\
\hline${ }^{*} \mathrm{p}<0.05$, * & 0.01 & & & & & & & & & & \\
\hline
\end{tabular}

The results of the multiple linear regression analysis for BI gain after propensity score matching for GNRI are shown in Table 4. Propensity scores were calculated by logistic regression analysis including age, sex, $\mathrm{CCl}$, number of drugs, and fracture type as explanatory variables. GNRI positively affected the BI gain $(\beta=0.392,95 \%$ confidence interval [CI]: 0.001 to $0.351, p=0.039)$. 
Table 4

Liner regression analysis for Bl efficiency

\begin{tabular}{|lllll}
\hline & $\boldsymbol{B}$ & 95\% confidence interval & \\
\hline Variables & & Lower & Upper \\
\hline PS & -0.175 & -22.050 & 2.982 \\
\hline GNRI & 0.392 & 0.010 & 0.351 \\
\hline Serum albumin & 0.103 & -2.921 & 5.107 \\
\hline $\begin{array}{l}\text { PS (log-transformed propensity score) was calculated from log transformation of the propensity score for age, sex, Charlson } \\
\text { comorbidity index, number of drugs, and fracture type. }\end{array}$ & & \\
\hline GNRI: Geriatric Nutritional Risk Indexes & & \\
\hline
\end{tabular}

The results of the logistic regression analysis are shown in Table 5. The incidence of a subsequent fall was correlated with serum albumin (odds ratio $0.033,95 \% \mathrm{Cl}: 0.002$ to $0.477, \mathrm{p}=0.012$ ). Propensity scores were calculated by logistic regression analysis including age, sex, $\mathrm{CCl}$, number of drugs, and fracture type as explanatory variables.

Table 5

Logistic regression analysis for subsequent fall

\begin{tabular}{|lllll|}
\hline Variables & Odds ratio & 95\% confidence interval & U-value \\
\hline PS & & Lower & Upper & 0.406 \\
\hline GNRI & 18.987 & 0.018 & 19590.442 & 0.559 \\
\hline Serum albumin & 1.033 & 0.926 & 1.153 & 0.477 \\
\hline
\end{tabular}

PS (log-transformed propensity score) was calculated from log transformation of the propensity score for age, sex, Charlson comorbidity index, number of drugs, and fracture type.

GNRI: Geriatric Nutritional Risk Indexes

\section{Discussion}

The results of this retrospective cohort study revealed two aspects concerning nutrition status in patients with DRF. First, this study suggested that malnutrition was a risk factor for reduced ADL in older patients after DRF. Our results indicate that low serum albumin levels are associated with a risk of falling after DRF (Tables 3 and 5). This study supports the hypothesis that better nutritional status is associated with improved ADL for older patients after DRF. To our knowledge, this is the first study to show the impact of nutrition status on ADL in patients with DRF.

First, we found that malnutrition may lower the performance of ADL of older patients after DRF. There are several reports on the relationship between nutritional status and ADL, and poor nutritional status is associated with lower ADL [19, 20, 21]. Osta et al. reported that malnutrition was associated with lower education levels and older age, length of hospital stay, complications, multidrug use, and decreased ADL [19]. The prevalence of malnutrition in the elderly was reported to be $13.5 \%$ by Osta et al. and $17.9 \%$ by Krichamoothy et al [20, 21]. Similarly, our study found that $13.5 \%$ of elderly DRF patients had malnutrition. Assessment of nutritional status after DRF may improve ADL by improving nutritional status

Second, we show that low serum albumin may increase the risk of a subsequent fall after DRF. In a previous study on fall risk, Mazur et al. reported that albumin $<32 \mathrm{~g} / \mathrm{L}$, in addition to age $\geq 76$ years, $\mathrm{BMI}<23.5$, Mini-Mental State Examination $<20, \mathrm{BI}<65$, hemoglobin $<$ $7.69 \mathrm{mmol} / \mathrm{L}$, serum protein $<70 \mathrm{~g} / \mathrm{L}$, and calcium level $<2.27 \mathrm{mmol} / \mathrm{L}$ were risk factors for falls in hospitalized elderly patients [22]. Galet et al. reported that the rate of readmission hospitalizations among fallers increased from 15.6-17.4\% between 2010 and 2014 , proposing that social support and a fall prevention program are required [23]. In this study, GNRI, serum album, BI at admission, and CCI were identified as factors related to subsequent falls. Furthermore, a logistic regression analysis using propensity score matching for the probability of subsequent falls showed that serum albumin had an influence on the probability of subsequent falls. Hypoalbuminemia may be associated 
with falls because it leads to insufficient muscle synthesis and decreases in skeletal muscle mass, resulting in decreased balance and gait ability. These results suggest the necessity of introducing nutritional assessment and a fall prevention program in elderly DRF patients.

There was also no correlation between BMD and subsequent falls after DRF in this study. Patel et al. described the relationship between osteoporosis and falls as fall-related risk factors are common in older women referred for open access bone densitometry [24]. In this study, we examined the rate of falls after DRF, and it is possible that the lack of correlation between BMD and falls in our study was due to bias as patients with high activity levels had higher frequency of DRF. In addition, $15.7 \%$ of patients used medications to treat osteoporosis before the DRF, which may also have influenced the results. In the future, it is necessary to examine the relationship between osteoporosis drugs and bone density and subsequent falls.

This study has a few limitations. First, the assessment of muscle strength, gait function, balance and postoperative nutritional assessment in patients with DRF was inadequate. In the future, it is necessary to examine the risk of falling by evaluating walking function, balance, and nutrition status during the postoperative follow-up period. Secondly, the verification of the life situation and the history of falls were insufficient, which should be verified in terms of their relationship with ADL.

\section{Conclusion}

This study showed that malnutrition is related to the ability to resume ADL in elderly patients with DRF. Furthermore, low serum albumin levels may increase the risk of subsequent falls after DRF. Nutrition assessment and fall prevention programs may be of great benefit to older patients with DRF.

\section{Abbreviations}

$\mathrm{BI}$

Barthel Index

BMI

Body Mass Index

BMD

Bone Mineral Density

$\mathrm{CCl}$

Charlson Comorbidity Index

DRF

Distal Radius Fracture

GNRI

Geriatric Nutritional Risk Indexes

PS

log-transformed propensity score

\section{Declarations}

\section{Acknowledgements}

Not applicable.

\section{Conflict of interest and sources of funding}

None declared.

\section{Authors' contributions}

All authors helped with date collection and contributed to the writing and critical revisions for intellectual content and final approval of the article.

\section{Funding}

There is no funding for the current study. 
Availability of data and materials

The datasets used/or analyzed during the current study are available from the corresponding author on reasonable request.

\section{Ethics approval and consent to participate}

The study protocol was reviewed and approval by the Committee on Ethics and the institutional review board of Nihon University Hospital and Osumi Hospital. Because this study was retrospective, the requirement for informed consent was waived.

\section{Consent for publication}

Not applicable.

\section{Competing interests}

All authors declare that they have no competing interests.

\section{References}

1. Nellans KW, Kowalski E, Chung KC. The epidemiology of distal radius fractures. Hand Clin. 2012;28(2):113-25.

2. Jupiter J. Future treatment and research directions in distal radius fracture. Hand Clin. 2012;28(2):245-8.

3. Porrino JA Jr, Maloney E, Scherer K, Mulcahy H, Ha AS, Allan C. Fracture of the distal radius: epidemiology and premanagement radiographic characterization. AJR Am J Roentgenol. 2014;203(3):551-9.

4. Melton LJ 3rd, Chrischilles EA, Cooper C, Lane AW, Riggs BL. How many women have osteoporosis? J Bone Miner Res 1992;7(9):100510.

5. Dewan N, MacDermid JC, Maclntyre NJ, Grewal R. Therapist's practice patterns for subsequent fall/osteoporotic fracture prevention for patients with a distal radius fracture. J Hand Ther. 2019; 32(4):497-506.

6. Dewan N, MacDermid JC, Grewal R, Beattie K. Risk factors predicting subsequent falls and osteoporotic fractures at 4 years after distal radius fracture-a prospective cohort study. Arch Osteoporos. 2018;13(1):32.

7. Louer CR, Boone SL, Guthrie AK, Motley JR, Calfee RP, Wall LB. Postural Stability in Older Adults with a Distal Radial Fracture. J Bone Joint Surg Am. 2016;98(14):1176-82.

8. Demura S, Yamada T, Kasuga K. Severity of injuries associated with falls in the community dwelling elderly are not affected by fall characteristics and physical function level. Arch Gerontol Geriatr. 2012;55(1):186-9.

9. Hodsman AB, Leslie WD, Tsang JF, Gamble GD. 10-year probability of recurrent fractures following wrist and other osteoporotic fractures in a large clinical cohort: an analysis from the Manitoba Bone Density Program. Arch Intern Med. 2008;168(20):2261-7.

10. Rouzi AA, Al-Sibiani SA, Al-Senani NS, Radaddi RM, Ardawi MS. Independent predictors of all osteoporosis-related fractures among healthy Saudi postmenopausal women: the CEOR Study. Bone. 2012;50(3):713-22.

11. Pluijm SM, Smit JH, Tromp EA, Stel VS, Deeg DJ, Bouter LM, Lips P. A risk profile for identifying community-dwelling elderly with a high risk of recurrent falling: results of a 3-year prospective study. Osteoporos Int. 2006;17(3):417-25.

12. Dewan N, MacDermid JC, Grewal R, Beattie K. Risk factors predicting subsequent falls and osteoporotic fractures at 4 years after distal radius fracture-a prospective cohort study. Arch Osteoporos. 2018;13(1):32.

13. Lee JK, Yoon BH, Oh CH, Kim JG, Han SH. Is Sarcopenia a Potential Risk Factor for Distal Radius Fracture? Analysis Using Propensity Score Matching. J Bone Metab. 2018;25(2):99-106.

14. Shannon K, Elle MG , Melissa HR , Diana GP. Nutrition Status, Bone Mass Density, and Selective Serotonin Reuptake Inhibitors. Prev Med 2018; 113, 62-67.

15. Tae KY, , Soo HK, Jiyong Kwak, Hong KK, Tyler HR. Association Between Osteoporosis and Age-Related Macular Degeneration: The Korea National Health and Nutrition Examination Survey. Invest Ophthalmol Vis Sci 2018; 59 (4):132-142.

16. Adly NN, Abd-El-Gawad WM, Abou-Hashem RM. Relationship Between Malnutrition and Different Fall Risk Assessment Tools in a Geriatric In-Patient Unit. Aging Clin Exp Res. 2019. Sep 3.

17. D'Hoore W., Sicotte C., Tilquin C. Risk adjustment in outcome assessmen: the Charlson comorbidity index. Methods Inf Med. 1993;32(5):382-387. 
18. Bouillanne O, Morineau G, Dupont C, Coulombel I, Vincent JP, Nicolis I, Benazeth S, Cynober L, Aussel C. Geriatric Nutritional Risk Index: a new index for evaluating at-risk elderly medical patients. Am J Clin Nutr. 2005;82(4):777-83.

19. Hsu YH, Chou MY, Chu CS, Liao MC, Wang YC, Lin YT, Chen LK, Liang CK. Predictive Effect of Malnutrition on Long-Term Clinical Outcomes among Older Men: A Prospectively Observational Cohort Study. J Nutr Health Aging. 2019;23(9):876-882.

20. El Osta N, El Arab H, Saad R, Rabbaa Khabbaz L, Fakhouri J, Papazian T, El Osta L. Assessment of nutritional status of older patients attending a tertiary hospital in Middle Eastern country. Clin Nutr ESPEN. 2019;33:105-110.

21. Krishnamoorthy Y, Vijayageetha M, Kumar SG, Rajaa S, Rehman T. Prevalence of malnutrition and its associated factors among elderly population in rural Puducherry using mini-nutritional assessment questionnaire. J Family Med Prim Care. 2018;7(6):1429-1433.

22. Mazur K, Wilczyński K, Szewieczek J. Geriatric falls in the context of a hospital fall prevention program: delirium, low body mass index, and other risk factors. Clin Interv Aging. 2016;11:1253-1261.

23. Galet C, Zhou Y, Eyck PT, Romanowski KS. Fall injuries, associated deaths, and 30-day readmission for subsequent falls are increasing in the elderly US population: a query of the WHO mortality database and National Readmission Database from 2010 to 2014 . Clin Epidemiol. 2018; 8;10:1627-1637.

24. Patel S, Tweed K, Chinappen U. Fall-related risk factors and osteoporosis in older women referred to an open access bone densitometry service. Age Ageing. 2005;34(1):67-71. 